\title{
Sliding mode control strategy based lead screw control design in electromechanical tracking drive system
}

\author{
Tran Duc Chuyen ${ }^{1}$, Van Hai Nguyen ${ }^{2}$, Phuong Nam Dao ${ }^{3}$, Nguyen Anh Tuan ${ }^{1}$, Nguyen Van Toan ${ }^{1}$ \\ ${ }^{1}$ University of Economics-Technology for Industries, Hanoi, Vietnam \\ ${ }^{2} \mathrm{Phu}$ Tho College of Technology and Agroforestry, Phu Tho, Vietnam \\ ${ }^{3}$ School of Electrical Engineering, Hanoi University of Science and Technology, Hanoi, Vietnam
}

\begin{tabular}{l} 
Article Info \\
\hline Article history: \\
Received Jun 21, 2021 \\
Revised Feb 1, 2022 \\
Accepted Feb 8, 2022 \\
\hline Keywords: \\
Lead screw \\
Nonlinear control \\
Position control \\
Servo motor control \\
Sliding mode control \\
Tracking drive system
\end{tabular}

\begin{abstract}
This article presents the research synthesis method of electromechanical tracking system for lead screw control using alternating current (AC) servo motors applied in machine tools, based on the framework of sliding mode control method and the state observer. Control algorithms are capable of compensating for perturbation components, with a state observation to be established to evaluate and compensate for uncertain nonlinear components. The chattering reduction techniques of sliding mode surface are proposed to improve the control effectiveness. The research results are verified by simulation on MATLAB-Simulink, showing that the proportional integral derivative (PID) controller has not met the control quality, but requires the sliding mode control law and state observation as proposed. Then this tracking drive system will work with better quality and can be developed for lead screw system of machine tool. The research results in the paper are also the completed development for calculating, designing, and manufacturing intelligent electrical drive systems in industrial applications.
\end{abstract}

This is an open access article under the CC BY-SA license.

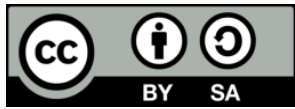

\section{Corresponding Author:}

Phuong Nam Dao

School of Electrical Engineering, Hanoi University of Science and Technology

Số 1 Đại Cồ Việt, Bách Khoa, Hai Bà Trưng, Hà Nội, Vietnam

Email: nam.daophuong@hust.edu.vn

\section{INTRODUCTION}

The old electric drive systems of machine tools in the past in industry are often applied by transmission systems using direct current (DC) motors with tool drives, hydraulic cylinders, with some manufacturers such as Sendday and Fuji [1]-[5]. However, these transmission systems often change speed, stop-brake-reverse, so there is always damage, which must be repaired, due to the existence of brushes, and electric commutators. Therefore, the stability and accuracy for the system to work is not high compared to the automatic electric drive system using alternating current (AC) servo motor [6]-[9].

The servo drive system always meets the requirements of very low speed control, as well as highspeed control, with many different working modes such as: stop mode, braking mode, reversing mode as well as stop mode easy, especially this transmission is less prone to damage and always works stably, and accurately. Moreover, at present, modern control techniques (optimal control, adaptive control, nonlinear control, sustainable control) and intelligent control (fuzzy logic control, neural network control, mobile algorithm) transmission and artificial intelligence is growing strongly [4], [6], [10]-[15]. Therefore, the speed stability, accurate control for electric transmission systems such as: control of lead screw for table movement, feed movement, spindle movement, and use of servo motors. Therefore, this modern control method is the optimal control method for computer numerical control (CNC) numerical control machine tools [16]-[22]. Syriac and Chiddarwar in [20], proposed an algorithm to reduce the tracking error on the rotation axis of the 
electromechanical tracking system with different thread pitch and its influence on the lead screw. In [23] studies the algorithm to evaluate the lead screw system applied to the hydraulic control system. Syriac and Chiddarwar [20], Tian et al. [23] both only study theory and stop at simulation, but have not entered into experimental and control programming. As mentioned above, the lead screw drive system for machine tools has the characteristic that during the working process there are always impact disturbances such as friction force, elastic moment, the effect of clearance when reversing rotation, jet, and affects the quality of the controller causing errors when controlling [2], [5], [6], [9], [14], [17], [18], [24].

This paper presents the problem of improving the quality of the position tracking controller for the automatic control system of the lead screw using AC servo motors applied in machine tools. In industrial production, CNC processing machines such as lathes, milling machines, and drilling machines [25]. The simulation research results will be the basis for calculation research, system design, evaluation, setting up the control algorithm of the tracking electric drive system, and in order to apply it to the actual production in the industry today, [8], [10], [12], [15]-[20].

\section{BUILDING MATHEMATICAL MODEL FOR AN ELECTRIC DRIVE SYSTEM}

In this part, the proposed controller is synthesized for a tracking electric drive system after considering the mathematical model of lead screw is being as: for machine tools that use servo motor driven lead screw, on the axis of rotation of the device is performed separately, so there is no loss of generality when we consider the dynamics of the screw. The drivetrain tracking to this position. From there, we have a model of the control structure of the electromechanical drive system of a machine tool using an AC servo motor to control a ball screw as shown in Figure 1, component $J_{\text {motor }}$ is the moment of inertia of the motor attached to the lead screw with flexible coupling, $\omega$ angular speed represents the control position of the motor with the lead screw, [3], [6], [16], [19]. Then we go to survey the transmission model of the electromechanical control system of the lead screw of the processing machine as shown in Figure 2, including: L length of ball screw, $\mathrm{x}(\mathrm{t})$ displacement control value of knife, $\mathrm{mt}$ weight of the tool table attached to the lead screw, in addition, there are brackets, joints, seat bases, and nuts.

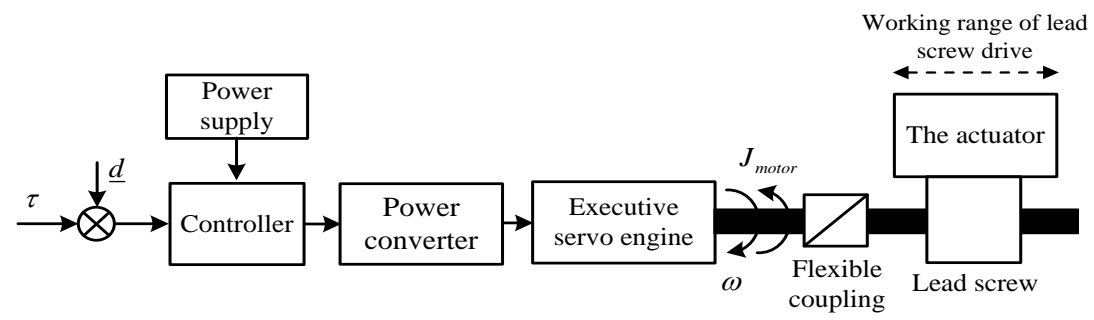

Figure 1. Model of electromechanical tracking drive system controlling lead screw using servo motor

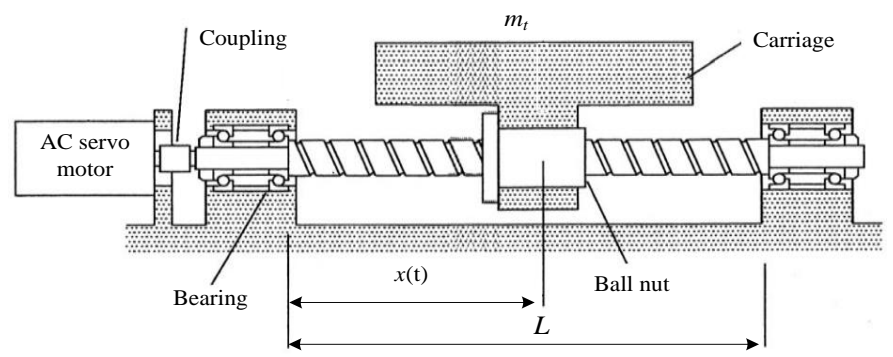

Figure 2. The transverse slide drive system controls the lead screw of CNC machine tools

Assuming that the transverse slide moves with a horizontal velocity, the friction between the lead screw and the nut, the lead screw system and the guide rod is said to always have nonlinear uncertainties. From the model is described as Figure 1; Figure 2, studying the dynamic model of the electromechanical tracking drive system controlling the lead screw with the input of the system torque $\tau$, component $\underline{d}$ is the noise signal, $\theta$ is the angular speed component of the motor shaft. The output is the position of the 
reciprocating rotation angle of the lead screw $x$. Diagram the drive system block from the control signal to the position of the lead screw device system $x$ is shown in Figure 3.

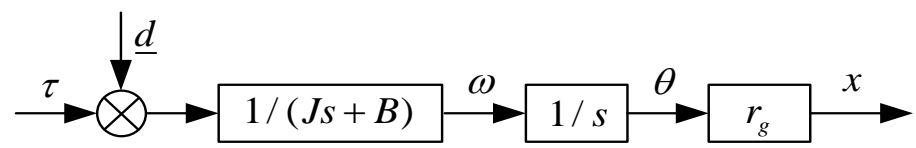

Figure 3. Structure diagram of the electromechanical tracking drive system of the lead screw system

In which, the engine torque will generate rotation of the motor shaft with the influence of moment of inertia $\mathbf{J}$ and viscous friction $\mathrm{B}$, [17], [20], [25]. Component $r_{g}$ is the conversion factor from the angular speed (or position) of the motor shaft to the reciprocating position of the lead screw system with the following relationship:

$$
\omega(t)=\frac{\dot{x}(t)}{r_{g}}
$$

From the structure diagram we have:

$$
\ddot{x}=-\frac{B \dot{x}}{J}+\frac{r_{g} \tau}{J}-d
$$

Here we put $a=\frac{B}{J} ; b=\frac{r_{g}}{J} ; u=\tau$, from here we have the equation describing the lead screw control system for machine tools described as the following equation:

$$
\ddot{x}=-a \dot{x}+b u-d
$$

With the input control signal of the system as the craft axis of machine set torque, the control synthesis in sliding mode is performed is being as:

\section{THE CONTROLLER SYNTHESIS METHOD IN SLIDING MODE}

The synthesize controller in sliding mode: Let $x_{d}$ be the desired trajectory, define $e=x_{d}-x$ as the tracking error. The control structure here is implemented as a closed-loop structure, then only the output reciprocating position and output velocity of the lead screw control system are measured and fed back to create a control law. The sliding variable is selected is being as:

$$
s=\dot{e}+c e
$$

Since the tracking error will converge to zero in an exponential form, the convergence speed depends on the choice of the coefficient with $\mathrm{c}>0$, then the error is $\lim _{t \rightarrow \infty} e=0$ after a period of time $t \geq t_{0}$, the tracking error is within the range acceptable behavior of the device. Substituting the value $e=x_{d}-x$ in (4) and differential with time we have:

$$
\dot{s}=\ddot{e}+c \dot{e}=\ddot{x}_{d}-\ddot{x}+c \dot{e}=\ddot{x}_{d}+a \dot{x}-b u+d+c \dot{e}
$$

In this study, it is expected that the evaluation error components will be zero. Thus, we must choose the constant evaluation rule on the basis of Lyapunov function for expression (5) is being as:

$$
V_{1}=\frac{1}{2} s^{2}
$$

Differentiating (6) with respect to time we have:

$$
\dot{V}_{1}=s \dot{s}=s\left(\ddot{x}_{d}+a \dot{x}-b u+d+c \dot{e}\right)
$$


According to the principle of stability theory of Lyapunov function, it is necessary to choose the control signal is being as:

$$
u=\frac{1}{b}\left[\ddot{x}_{d}+a \dot{x}+c \dot{e}+\hat{d}+k \operatorname{sgn}(s)\right]
$$

The selection according to (8) is to ensure according to the property of the negative Lyapunov function. Thence inferred:

$$
\begin{aligned}
& \dot{V}_{1}=s\left(\ddot{x}_{d}+a \dot{x}-b\left[\frac{1}{b}\left[\ddot{x}_{d}+a \dot{x}+c \dot{e}+d+k \operatorname{sgn}(s)\right]\right]+d+c \dot{e}\right) \\
& =s\left(\ddot{x}_{d}+a \dot{x}+\ddot{x}_{d}-a \dot{x}-c \dot{e}-k s g n(s)-d+d+c \dot{e}\right)=s(-k s g n(s))=-k|s| \leq 0
\end{aligned}
$$

The proposed control law as above has ensured the convergence of state variables according to control theory with Lyapunov control function. Design and analysis of stability on the basis of a state observer: For the lead screw drive system, depending on the type and size of the lead screw, during the system's operation under various conditions, there are many types of disturbances affecting the system such as force friction, the influence of the gap, the elastic factor and the stiffness of the lead screw, and the machining reaction. This noise has different characteristics that affect the signal reception from the controller. When the lead screw rotates, the noise component due to the reaction also has a small variation with time, then we can apply the state observer proposed by [5], [13] is being as:

$$
\begin{aligned}
& \dot{\hat{d}}=c_{1}(\hat{\delta}-\dot{x}) \\
& \dot{\hat{\delta}}=-\hat{d}+b u-c_{2}(\hat{\delta}-\dot{x})-a \dot{x}
\end{aligned}
$$

where, $\hat{d}$ is an estimate of $d$ and $\hat{\delta}$ is an estimate of $\dot{x}, \mathrm{c}_{1}>0, \mathrm{c}_{2}>0$, similar to the above with the expectation that the evaluation error component will gradually approach zero. We choose the Lyapunov function is being as:

$$
V_{2}=\frac{1}{2 c_{1}} \tilde{d}^{2}+\frac{1}{2} \tilde{\delta}^{2}
$$

Because for the set of observers, it is necessary to observe the real unmeasured components (it is necessary to estimate these components) to ensure a stable system (according to the theory of stability of Lyapunov functions). For $\tilde{d}=d-\hat{d}, \tilde{\delta}=\dot{x}-\hat{\delta}$. The differential (12) of the Lyapunov function has the form:

$$
\dot{V}_{2}=\frac{1}{c_{1}} \tilde{d} \dot{\tilde{d}}+\tilde{\delta} \dot{\tilde{\delta}}=\frac{1}{c_{1}} \tilde{d}(\dot{d}-\dot{\hat{d}})+\tilde{\delta}(\ddot{x}-\dot{\hat{\delta}})
$$

Substituting (10), (11) and (2) into (13) we get the following:

$$
\begin{aligned}
& \dot{V}_{2}=\frac{1}{c_{1}} \tilde{d}\left(\dot{d}-c_{1}(\hat{\delta}-\dot{x})\right)+\tilde{\delta}\left(-a \dot{x}+b u-d-\left(-\hat{d}+b u-c_{2}(\hat{\delta}-\dot{x})-a \dot{x}\right)\right) \\
& =\frac{1}{c_{1}} \tilde{d} \dot{d}-\tilde{d}(\hat{\delta}-\dot{x})+\tilde{\delta}\left(-d+\hat{d}+c_{2}(\hat{\delta}-\dot{x})\right)=\frac{1}{c_{1}} \tilde{d} \dot{d}+\tilde{d} \tilde{\delta}+\tilde{\delta}\left(-\tilde{d}-c_{2} \tilde{\delta}\right)=\frac{1}{c_{1}} \tilde{d} \dot{d}-c_{2} \tilde{\delta}^{2}
\end{aligned}
$$

When the noise $\mathrm{d}$ is small in time and limited, with $\mathrm{c}_{1}$ having a suitable value, then is obtained $\left(1 / c_{1}\right) \cdot \dot{d} \approx 0$, here it is appropriate to choose $c_{2}$. So, we have:

$$
\dot{V}_{2}=\frac{1}{c_{1}} \tilde{d} \dot{d}-c_{2} \tilde{\delta}^{2} \leq 0
$$

Thus, noise $\mathrm{d}$ can be estimated by designing a noise observer and for noise compensation can be implemented in feedback control. Design a controller in sliding mode with an observer that evaluates the nonlinear component: Same as above, here we choose the sliding variable as expression (4), (5) with $c>0$, we choose the Lyapunov function is being as:

$$
V_{3}=\frac{1}{2} s^{2}
$$

From there, replace the value $e=x_{d}-x$ in (16) and and time differential expression (16) get: 


$$
\dot{V}_{3}=s \dot{s}=s\left(\ddot{x}_{d}+a \dot{x}-b u+d+c \dot{e}\right)
$$

To reduce oscillation on the sliding surface, it is possible to build and select the control signal is being as:

$$
u=\frac{1}{b}\left[\ddot{x}_{d}+a \dot{x}+c \dot{e}+\hat{d}+k s g n(s)\right]
$$

With $\hat{d}$ being the component of the estimated values of $d$ and $\tilde{d}=d-\hat{d}$. We get:

$$
\begin{aligned}
& \dot{V}_{3}=s\left(\ddot{x}_{d}+a \dot{x}+d+c \dot{e}-b\left[\frac{1}{b}\left[\ddot{x}_{d}+a \dot{x}+c \dot{e}+\hat{d}+k s g n(s)\right]\right]\right) \\
& =s\left(\ddot{x}_{d}+a \dot{x}-\ddot{x}_{d}-a \dot{x}-c \dot{e}-\hat{d}-k s g n(s)+d+c \dot{e}\right)=s(d-\hat{d}-k s g n(s))=\tilde{d} s-k|s|
\end{aligned}
$$

With the coefficient $k$ chosen satisfying $k \geq|\tilde{d}|$, we can get:

$$
\dot{V}_{3}=\tilde{d} s-k|s| \leq 0
$$

The Lyapunov function of a fully closed system can be expressed as:

$$
V=V_{2}+V_{3}=\frac{1}{2 c_{1}} \tilde{d}^{2}+\frac{1}{2} \tilde{\delta}^{2}+\frac{1}{2} s^{2}
$$

Differentiate (21), we get:

$$
\dot{V}=\dot{V}_{2}+\dot{V}_{3}=\frac{1}{c_{1}} \tilde{d} \dot{\tilde{d}}+\tilde{\delta} \dot{\tilde{\delta}}+s \dot{S}
$$

Substituting (13) and (20) into (22), we have:

$$
\dot{V}=\dot{V}_{2}+\dot{V}_{3}=\frac{1}{c_{1}} \tilde{d} \dot{d}-c_{2} \tilde{\delta}^{2}+\tilde{d} s-k|s| \leq 0
$$

Then get the value $\dot{V} \leq 0$. Limiting oscillation on the sliding surface for the controller: one limitation of the sliding mode control mode is the chattering phenomenon on the sliding surface, which negatively affects the system and the actuator. To limit the oscillation on the sliding surface, we use the saturation function instead of the sign function in the control law (18), [2]. The saturation (sat) function is described as (24). From there, we have the saturation function graph as shown in Figure 4 as shown in. Then, it will reduce the oscillation on the sliding surface from using the saturation function instead of the sign function, bringing high results for the control system, [2], [8], [14], [25].

$$
\operatorname{sat}(s)=\left\{\begin{array}{l}
1, s>\Delta \\
k s,|s| \leq \Delta, k=1 / \Delta \\
-1 s<-\Delta
\end{array}\right.
$$

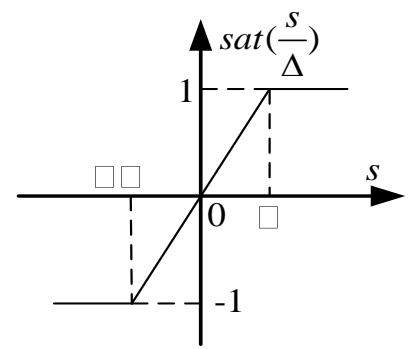

Figure 4. The saturation function graph

\section{RESULTS AND DISCUSSION}

To get an assessment of the quality of the proposed controller, the authors build simulations on MATLAB-Simulink for the model object of a ball screw system using an AC servo motor. This is a permanent magnet synchronous motor (PMSM) with a conventional proportional integral derivative (PID) controller and a slip controller has been proposed, [8], [9], [11]. Parameters $V_{P}, V_{I}$ are selected on the basis of experimental method Zeigler Nichols. After choosing parameters $V_{P}, V_{I}$, we can calculate parameters $V_{P}$ 
and d. However, due to the experimental design, to improve the control quality: short transient time and small overshoot, it is necessary to adjust two more parameters $\mathrm{Vp}$ and $\mathrm{d}$. The set of correction parameters found are: $\mathrm{V}_{\mathrm{P}}=0.01 ; \mathrm{d}=0.98$ (with $\mathrm{T}=0.002$ ). Quality of proportional integral (PI) controller after selection calculation: $\mathrm{K}_{\mathrm{P}}=0.3 ; \mathrm{K}_{\mathrm{I}}=0.0001$. In addition, the authors use PID design control software to design the controller. Technical parameters include: speed $0-12 \mathrm{~mm} / \mathrm{s}$, load $95 \mathrm{KgN}$, fixed-length aperture full-stroke lead screw $\mathrm{L}=500 \mathrm{~mm}$, with moving distance to the left of lead screw $\mathrm{L}_{1}=19 \mathrm{~cm}$, right shift $\mathrm{L}_{2}=23 \mathrm{~cm}$, maximum length of lead screw excluding joints is $500 \mathrm{~mm}$, and minimum length is $5 \mathrm{~mm}$ in screw pitch of lead screw. The outer width of the lead screw system is $120 \mathrm{~mm}$, the tool table width is $105 \mathrm{~mm}$, and the toolpath length is $120 \mathrm{~mm}$. Travel time to the end of the journey with the maximum speed $\mathrm{t}=3.15 \mathrm{~s}$ with the parameters: $R_{u}=10 \Omega, L_{u}=10 \mathrm{mH}, \frac{K}{J}=1388.61(\mathrm{~N} / \mathrm{A}) /\left(\mathrm{kgm}^{2}\right)$. AC servo motor with driver panasonic MADDT1207 has parameters: motor power $\mathrm{P}=200 \mathrm{~W}$, rated speed $\mathrm{n}_{\text {rate }}=3000 \mathrm{rpm}$, current $\mathrm{I}=2$ A, voltage $\mathrm{U}=200 \mathrm{~V}$, frequency $50-60 \mathrm{~Hz}$, encoder counting $2500 \mathrm{~S} / \mathrm{R}$, and the motor shaft end has a soft joint that is linked to the lead screw system. Working structure with converted moment of inertia $J=0.12 \mathrm{kgm}^{2}$. To evaluate the results, we perform a position tracking simulation for the axis of the lead screw driver with the parameters given is being: $r_{g 1}=0.05 \mathrm{rad} / \mathrm{m}, J_{1}=0.03 \mathrm{kgm}^{2}, B_{1}=0.06 \mathrm{kgm}^{2} / \mathrm{s}, k_{1}=4000, \Delta=0.10$, $\mathrm{c}=15$, and $\mathrm{k}=50$.

Simulation results: performed with a conventional PID position controller as shown in Figure 5. The simulation results with the sliding mode controller and the noise observer are being as. Evaluation of results: comparing the value of the lead screw position tracking controller, we found that, with a conventional PID controller, the setup time for the system to follow the set signal is about $0.7 \mathrm{~s}$; the overcorrection is $7 \%$, the largest tracking error is about $12.3 \%$ Figure 5. With the sliding controller combined with the state observer, we have a set time for the drive system to tracking the signal as the set speed and the actual speed always follows the set value Figure 6, the noise signal estimation value d1 and the parameter estimation error of the controller show that a good working observer always provides full information about the controller Figure 7. Similarly, with the input control signal $\mathrm{u} 1(\mathrm{t})$ as shown in Figure 8, the quality of tracking the position of the lead screw system when using the proposed sliding controller as shown in Figure 9 is also better than that of the lead screw system with conventional PID controller simulation results Figure 5. Moreover, these results compare with the literature [19], [23], the results of this paper are better, because there are smaller tracking errors, leading to better control quality.

From the results of tracking the trajectory of the lead screw system device, we find that, with a conventional PID controller, the overdrive of the position controller is large, the transient time is large, and the error of tracking the end point trajectory of the controller is large. As for the proposed sliding controller combined with state observer, we find that the tracking quality of the controller has high accuracy. The actual trajectory of the lead screw system has captured the set trajectory with a very small error ( $\gg 0)$, the transient time is small, the overshoot is very small.

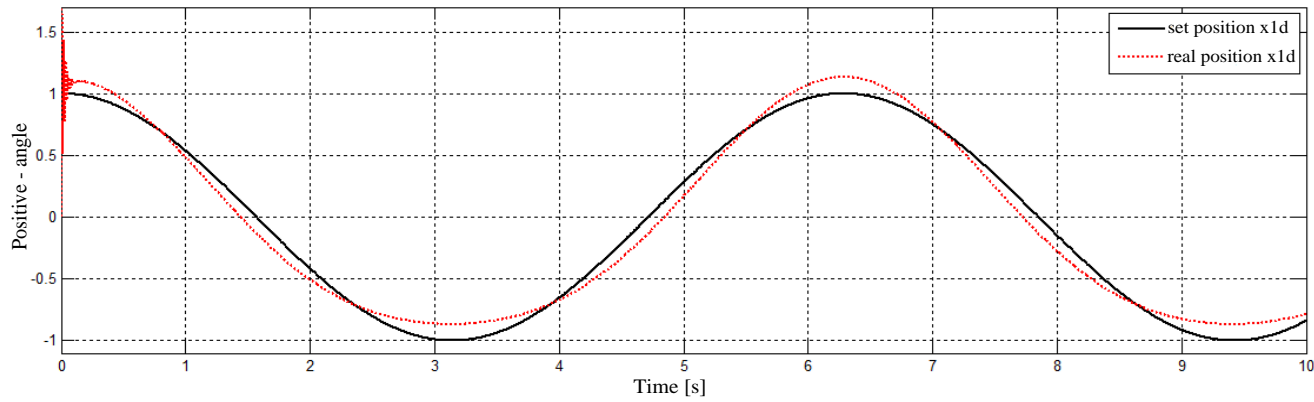

Figure 5. The rotational axis position of lead screw system when using PID controller

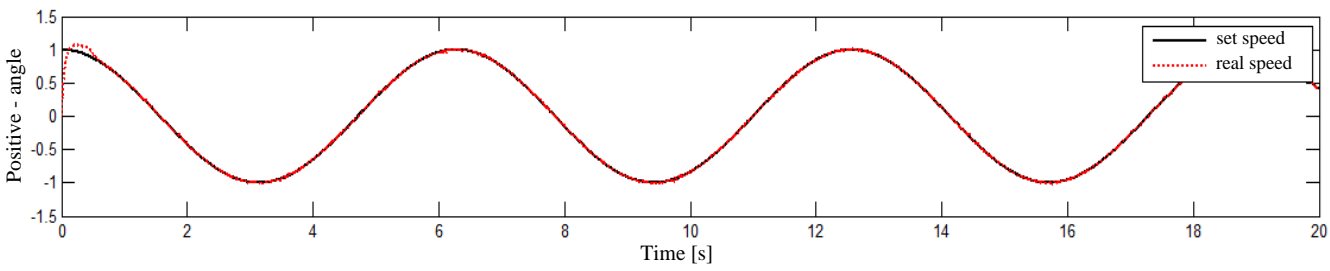

Figure 6. Real speed and set speed of lead screw system 

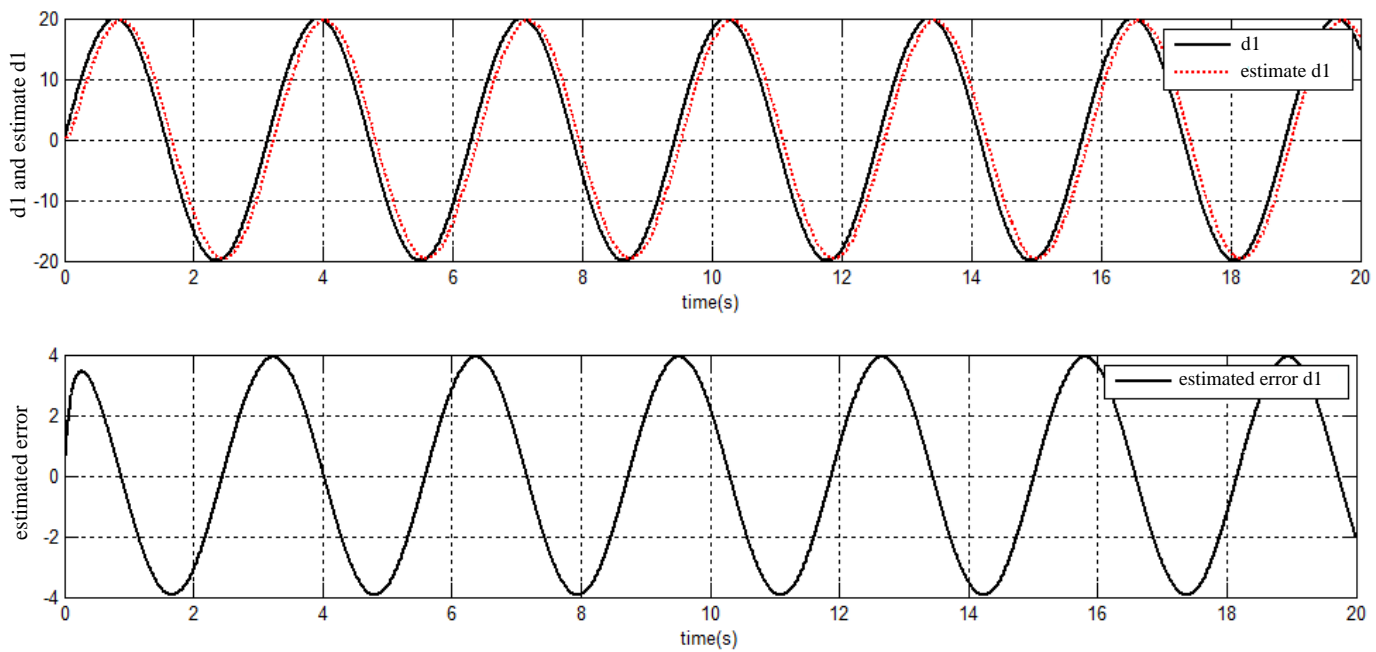

Figure 7. Result of noise signal estimation d1 and estimation error when the lead screw system is working

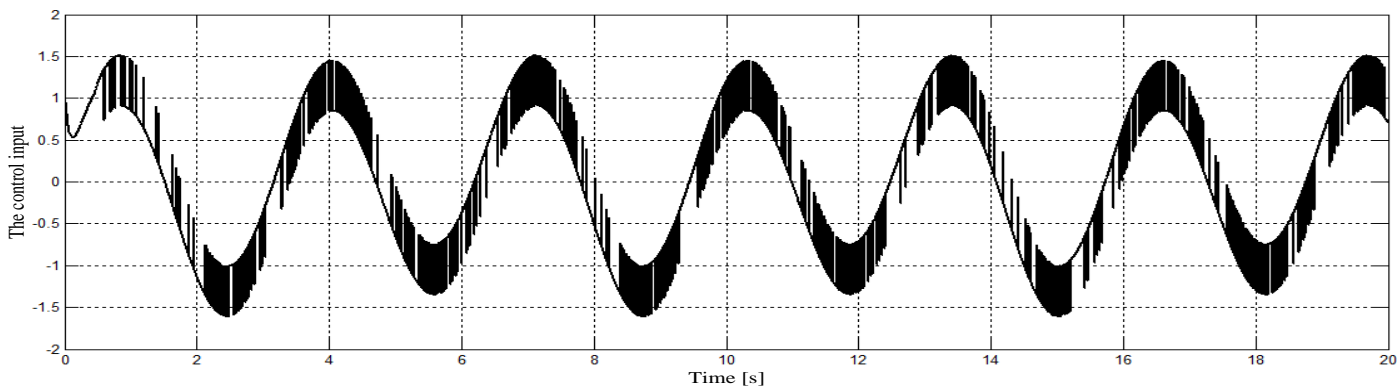

Figure 8. The control signal input $\mathrm{u} 1(\mathrm{t})$

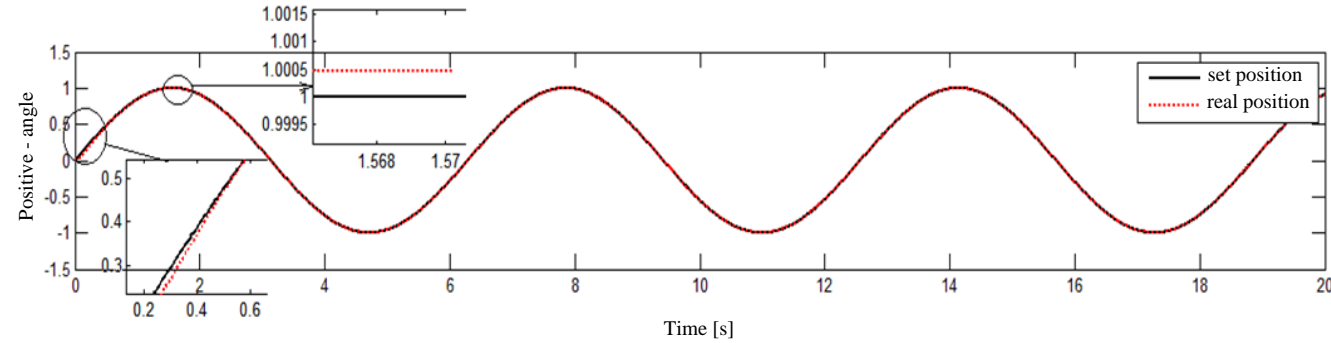

Figure 9. The axial position of the lead screw device when using the proposed sliding mode controller

Through the simulation results, the following observations are made: the control quality of the proposed sliding controller is much higher than that of the conventional PID controller: in terms of transient time, overcorrection, and tracking error. The controller and speed controller of the lead screw system has always been tracking according to the position and set speed with a small tracking error, after a short period of time. Therefore, the position controller of the lead screw control system always follows the set trajectory with a very small error, compared with previous works [17], [19], [20], [23], the results of this paper are better, which proves that the quality of the controller has met the control requirements with high accuracy for the CNC machine tool system. On the basis of the built-in state observer, the results show that the observer has evaluated the value of the controller's impact noise with a small tracking error. From there, we implement the sliding mode control law combined with noise compensation to ensure the stability of the system with the proposed control law. 


\section{CONCLUSION}

The article has synthesized the position tracking control algorithm for the lead screw electromechanical system using servo motor on the basis of control in sliding mode and state observer with high control quality and small tracking error. The control law is proven based on the Lyapunov stability theory. The results of simulation research on the basis of MATLAB-Simulink software have proved the correctness of the proposed controller algorithm, compared with previous studies, the proposed controller algorithm. The above can be applied in practice to improve control quality for many industrial and civil processing machinery and equipment.

\section{ACKNOWLEDGEMENTS}

This research was supported by research foundation funded by Faculty of Electrical Engineering, University of Economics-Technology for Industries, No. 456 Minh Khai Road, Hai Ba Trung district, Ha Noi Capital -Viet Nam National; http://www.uneti.edu.vn/.

\section{REFERENCES}

[1] M. Jufer, "Electric Drives: design methodology," John Wiley \& Sons, February 2013, doi: 10.1002/9781118622735.

[2] V. Utkin, J. Guldner, and J. Shi, "Sliding Mode Control in Electro-Mechanical Systems," CRC Press, January 2017, doi: $10.1201 / 9781420065619$.

[3] S. Filizadeh, "Electric Machines and Drives: Principles, Control, Modeling, and Simulation," CRC Press, February 2013, doi: $10.1201 / 9781315169651$.

[4] A. M. Annaswamy, "Robust Adaptive Control," in: Baillieul J., Samad T. (eds) Encyclopedia of Systems and Control. Springer, London, November 2014, doi: 10.1007/978-1-4471-5102-9_118-1.

[5] J. Pyrhönen, V. Hrabovcová, and R. S. Semken, "Electrical Machine Drives Control: An introduction," John Wiley \& Sons Ltd. United Kingdom, 2016, doi: 10.1002/9781119260479.

[6] A. Bacciotti, "Stability and Control of Linear Systems," Springer International Publishing, 2019, doi: 10.1007/978-3-030-024055 .

[7] A. Emadi, "Advanced Electric Drive Vehicles," CRC Press is an imprint of Taylor \& Francis Group, an Informa business, Springer International Publishing; USA, 2016, doi: 10.1201/9781315215570.

[8] M. Steinberger, M. Horn, and L. Fridman, "Variable-Structure Systems and Sliding-Mode Control from theory to practice," New York, NY, USA: Springer International Publishing, 2020, doi: 10.1007/978-3-030-36621-6.

[9] L. Keviczky, R. Bars, J. Hetthéssy, and C. Bányász, "Control Engineering: MATLAB Exercises," Publishing by Springer Nature Singapore Pte Ltd, USA, 2019, doi: 10.1007/978-981-10-8321-1_1.

[10] T. Zhang and J. Su, "Collision-free planning algorithm of motion path for the robot belt grinding system," Int. J. Adv. Robot. Syst., vol. 15, no. 4, pp. 1-13, July-August 2018, doi: 10.1177/1729881418793778.

[11] D. P. Nam, N. H. Quang, N. N. Tung, and T. T. H. Yen, "Adaptive dynamic programming algorithm for uncertain nonlinear switched systems," International Journal of Power Electronics and Drive Systems (IJPEDS), vol. 12, no. 1, pp. 551-557, March 2021, doi: http://doi.org/10.11591/ijpeds.v12.i1.pp551-557.

[12] M. Zaky, E. Touti, and H. Azazi, "Two-Degrees of Freedom and Variable Structure Controllers for Induction Motor Drives," Advances in Electrical \& Computer Engineering, vol. 18, no. 1, pp. 71-80, 2018, doi: 10.4316/AECE.2018.01009.

[13] S. Kim, K. Lee and K. Lee, "Singularity-Free Adaptive Speed Tracking Control for Uncertain Permanent Magnet Synchronous Motor," in IEEE Transactions on Power Electronics, vol. 31, no. 2, pp. 1692-1701, Feb. 2016, doi: 10.1109/TPEL.2015.2422790.

[14] Z. Dong, F. Xu, X. Sun, and W. Liu, "A Laser-Based On-Machine Measuring System for Profile Accuracy of DoubleHeaded Screw Rotor," Sensors, vol. 19, no. 23, p. 5059, November 2019, doi: 10.3390/s19235059.

[15] R. Mini, C. Saranya, H. Satheesh, and M. N. Dinesh, "Low Speed Estimation in Sensorless Direct Torque Controlled Induction Motor Drive Using Extended Kalman Filter," International Journal of Power Electronics and Drive Systems (IJPEDS), vol. 6, no. 4, pp. 819-830, December 2015, doi: 10.11591/ijpeds.v6.i4.pp819-830.

[16] J. Zhang, B. Zhang, G. Feng, and B. Gan, "Design and Analysis of a Low-Speed and High-Torque Dual-Stator Permanent Magnet Motor with Inner Enhanced Torque," in IEEE Access, vol. 8, pp. 182984-182995, 2020, doi: 10.1109/ACCESS.2020.3028425.

[17] Z. Li, J. Chen, G. Zhang, and M. Gan, "Adaptive Robust Control of Servo Mechanisms with Compensation for Nonlinearly Parameterized Dynamic Friction," in IEEE Transactions on Control Systems Technology, vol. 21, no. 1, pp. 194-202, Jan. 2013, doi: 10.1109/TCST.2011.2171966.

[18] M. R. Msukwa, E. W. Nshama, and N. Uchiyama, "Adaptive Sliding Mode Control with Feedforward Compensator for EnergyEfficient and High-Speed Precision Motion of Feed Drive Systems," in IEEE Access, vol. 8, pp. 43571-43581, 2020, doi: 10.1109/ACCESS.2020.2977395.

[19] Z. Ling, W. Zhao, J. Ji, and G. Liu, "Design of a New Magnetic Screw with Discretized PMs," in IEEE Transactions on Applied Superconductivity, vol. 26, no. 4, pp. 1-5, June 2016, doi: 10.1109/TASC.2016.2536651

[20] A. S. Syriac, and S. S. Chiddarwar, "Dynamic characteristics analysis of a lead screw by considering the variation in thread parameters," International Conference on Mechanical Power Transmission, IOP Publishing, vol. 624, no. 1, p. 012007, October 2019, doi: 10.1088/1757-899X/624/1/012007.

[21] A. Akpunar and S. Iplikci, "Runge-Kutta Model Predictive Speed Control for Permanent Magnet Synchronous Motors," Energies, vol. 13, no. 5, p. 1216, March 2020, doi: 10.3390/en13051216.

[22] S. Basaran and S. Sivrioglu, "Robust Variable Structure Controllers for Axial Active Magnetic Bearing," International Journal of Applied Mathematics Electronics and Computers, pp. 178-183, 2016, doi: 10.18100/ijamec.270081.

[23] T. Tian, W. Wu, J. Jiang, L. Zhu, K. Lu, and F. Blaabjerg, "Design Optimization of a Reluctance Lead Screw for Wave Energy Conversion," Energies, vol. 13, no. 20, p. 5388, Oct. 2020, doi: 10.3390/en13205388.

[24] M. Jasiewicz, and K. Miądlicki, "Implementation of an Algorithm to Prevent Chatter Vibration in a CNC System," Materials, vol. 12, no. 19, p. 3193 , Sept. 2019, doi: 10.3390/ma12193193. 
[25] T. Zhang, Y. Yu, and Y. Zou, “An Adaptive Sliding-Mode Iterative Constant-force Control Method for Robotic Belt Grinding Based on a One-Dimensional Force Sensor," Sensors, vol. 19, no. 7, p. 1635, April 2019, doi: 10.3390/s 19071635.

\section{BIOGRAPHIES OF AUTHORS}
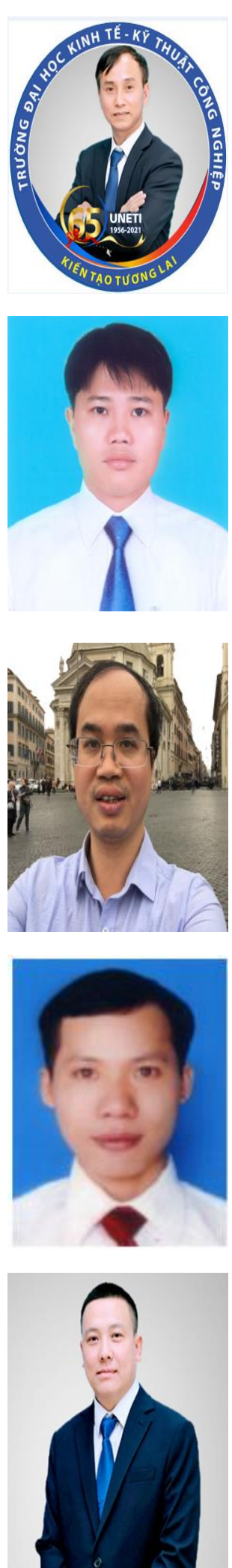

Tran Duc Chuyen (iD SC P received the Ph.D. degree in Industrial Automation from Le Qui Don Technical University (MTA), Hanoi, Vietnam in 2016. Now, works at Faculty of Electrical Engineering, University of Economics-Technology for Industries. He is currently the President of Council the Science of Faculty of Electrical Engineering. Tran Duc Chuyen's main researches: electric machine, drive system, control theory, power electronics and application, adaptive control, neural network control, automatic robot control, motion control, and artificial intelligence. He can be contacted at email: tdchuyen@uneti.edu.vn.

Van Hai Nguyen (D) 8d SC P was born in 1980. HCMC University of Technology and Education (HCMUTE) in 2008, and received M.S. automation degree 2011 and the Ph.D. degree in Control Engineering and Automation at Le Qui Don Technical University (MTA) in 2017. From 2002 to 2020, he was the Vice Dean of the Faculty of Electrical Engineering, currently he is the Head of the Training Department of Phu Tho College of Technology and Agroforestry of Vietnam. Main research direction: intelligent control, process control, drive system, power electronics and application, adaptive control, fuzzy logic control, automatic robot control, and motion control. He can be contacted at email: haind.nguyen@gmail.com.

Phuong Nam Dao (D) SC SC P received the Ph.D. degree in Industrial Automation from Hanoi University of Science and Technology, Hanoi, Vietnam in 2013. Currently, he holds the position as lecturer at Hanoi University of Science and Technology, Vietnam. His research interests include control of robotic systems and robust/adaptive, optimal control. He can be contacted at email: nam.daophuong@ hust.edu.vn.

Nguyen Anh Tuan (D) 8d SC P was born in 1984. He is working at the Faculty of Mechanical Engineering, University of Economics-Technology for Industries; Ministry of Industry and Trade the socialist republic of Vietnam. He received the Ph.D. degree in mechanical engineering from Hanoi University of Science and Technology, Hanoi, Vietnam in 2018. His research interests include precision engineering, impact of technological parameters on surface quality of workpiece cutting on tool machines. He can be contacted at email: natuan.ck@uneti.edu.vn.

Nguyen Van Toan (D) 8d SC P was born in 1982. He graduated as an Engineer of Electrical Engineering and Technology, majoring in Automation at University of Economic and Industrial Technology. Received a master's degree in Control Engineering and Automation from the University of Transport and Communications, 2013. From 2008 until now he has been a lecturer in the Faculty of Electrical, University of Economics-Technology for Industries; Ministry of Industry and Trade the socialist republic of Vietnam. Main research direction: intelligent control, PLC and microcontroller, industrial electrical control, and power supply system control. He can be contacted at email: nvtoan@uneti.edu.vn. 